\title{
Research on the Entrepreneurial Environment Element System of the Deeply Impoverished Area in Northeast Chongqing
}

\author{
Jianyu Ran1,2*, Ximin Yu², Donghao Ran² \\ ${ }^{1}$ School of Economics and Management, Southwest Jiaotong University, Chengdu, China \\ ${ }^{2}$ School of Business Administration, Chongqing Three Gorges University, Chongqing, China \\ Email: *ranjianyu@126.com
}

How to cite this paper: Ran, J. Y., Yu, X. M., \& Ran, D. H. (2020). Research on the Entrepreneurial Environment Element System of the Deeply Impoverished Area in Northeast Chongqing. Modern Economy, $11,965-976$.

https://doi.org/10.4236/me.2020.114071

Received: February 28, 2020

Accepted: April 24, 2020

Published: April 27, 2020

Copyright $\odot 2020$ by author(s) and Scientific Research Publishing Inc. This work is licensed under the Creative Commons Attribution International License (CC BY 4.0).

http://creativecommons.org/licenses/by/4.0/

(c) (i) Open Access

\begin{abstract}
The returned migrant workers' starting their own businesses in deeply impoverished areas is a vital way to realize rural vitalization. Therefore, optimizing the entrepreneurial environment in deeply impoverished areas is of great strategic significance. In order to optimize the entrepreneurial environment for returned migrant workers, it is required to firstly define the rural entrepreneurial environment elements needed by the returned migrant workers, so as to determine the rural entrepreneurial environment element system for returned migrant workers. In this article, the deeply impoverished area in northeast Chongqing is taken as an example, and a large sample survey on the migrant workers' requirements of entrepreneurial environment elements is conducted, and 23 entrepreneurial environment elements are covered in the subsequent questionnaire survey. Factor analysis helps to define the migrant workers' entrepreneurial environment element system: government and policy efficiency, production factor support, family and social support, entrepreneurial cost level, and business registration convenience. On this basis, measures are proposed to optimize the entrepreneurial environment of the deeply impoverished area.
\end{abstract}

\section{Keywords}

Deeply Impoverished Area, Entrepreneurial Environment, Element Composition

\section{Introduction}

The rural revitalization strategy is the basic strategy of our country. Under the 
guidance of the Party Central Committee's rural revitalization strategy, actively encouraging and advancing migrant workers to start businesses in deeply impoverished areas is an important approach to achieve the rural revitalization strategy and a vital way to help people get rid of poverty and become better-off. Entrepreneurial environment is a collection of external conditions for entrepreneurs to engage in entrepreneurial activities, including government policies, laws and regulations, socio-economic conditions, venture capital support, non-capital support, and entrepreneurship and management skills. Its essence is the resource element support of entrepreneurial activity. Entrepreneurial activities are the interactive process between entrepreneurs and entrepreneurial environment, and the process of entrepreneurs to create value by integrating and utilizing external resources. Entrepreneurs' cognition and evaluation of the entrepreneurial environment, as well as the formation of entrepreneurial intention and motivation, actually reflect the entrepreneurs' demand for entrepreneurial environmental resources. Therefore, in facilitating returned migrant workers to start their own businesses in deeply impoverished area, it is required to optimize the entrepreneurial environment in deeply impoverished area based on their needs for entrepreneurial environment elements. In this article the deeply impoverished area of northeast Chongqing is selected as an example, and the entrepreneurial environment element system is extracted based on the migrant workers' requirement for the entrepreneurial environment elements, and then measures are put forward to optimize the entrepreneurial environment.

\section{Research on Entrepreneurial Environment Elements in Review}

Overseas, Dill (1958) earlier divided the entrepreneurial environment elements into task environment elements and general environment elements. Selin (2018) has argued that the entrepreneurial environment comprises of the availability of venture capital, the presence of experienced entrepreneurs, skilled workforce, the accessibility of suppliers, the approachability of consumers and new markets, government intervention, peripheral availability of universities, land and facilities, convenient transportation, people's entrepreneurial attitude, availability of support services, people's living standards and other elements. Research by Thébaud (2015) has confirmed that the entrepreneurial environment elements are mainly composed of necessary environmental elements and supportive environmental elements, and the necessary environment elements include natural environment, technical environment, financing environment and talent environment; supportive environmental elements contain the institutional environment, cultural environment and social capital. Gnyawali \& Fogel (1994) have proposed that the entrepreneurial environment is an organic combination of multiple elements, including socioeconomic conditions, entrepreneurship and management skills, government policies and procedures, entrepreneurial funding support, and non-financial support for entrepreneurship. Research by Zoltan 
\& Saul (2018) has attested that the entrepreneurial environment mainly embraces family and support systems, financial resources, employees, customers, suppliers, local communities, government agencies, and cultural, political, and economic environment elements. Gartner \& Shane (1995) summarized the research results of Bruno and other scholars, and put forward 22 entrepreneurial environment elements as the integration and summary of the research on the entrepreneurial environment elements. In 1999, GEM first published the Global Entrepreneurship Observation Report. Subsequently, foreign scholars' research on the entrepreneurial environment elements has been deepened from the industrial level and social level. Patti \& Mudambi (2016) proposed the social network support content of the entrepreneurial environment elements; Nagler \& Naudé (2017) analyzed the social atmosphere element among the entrepreneurial environment elements; Hang (2016) proposed that social recognition, social norms and standards, entrepreneurial model demonstration and other elements should be included in entrepreneurial environment elements; Marian (2015) put forward the entrepreneurial environment elements such as the industrial agglomeration degree and the regional specialization degree; Katonáné (2015) suggested to reduce barriers to industry entry in their entrepreneurship policy framework. The research on entrepreneurial environment elements in China started relatively late, and was mainly application research with referring to the GEM framework. Among the representative studies, Chi (2002) raised a six-element system of entrepreneurial environment: entrepreneurial cultivation system, business incubation system, enterprise cultivation system, risk management system, successful reward system and entrepreneurial network system. The research by Xiao et al. (2018) has shown that the entrepreneurial environment elements include the natural environment, social environment, and economic environment, etc., including contents of policy and law, financial services, intellectual technology, social services, and industry; Zhang (2018) constructed the urban entrepreneurship environment elements from the aspects of economic foundation, service support, scientific and educational support, cultural support and environmental support. Chen \& Du (2018) confirmed that entrepreneurial environment elements include direct elements and indirect elements in their study.

The research on the entrepreneurial environment elements at home and abroad involves abundant contents, covering natural environment, social environment, industrial environment, resource support, infrastructure, government and policies, social atmosphere and attitude, etc. These results have provided valuable reference for studies into entrepreneurial environment elements of deep impoverished areas. However, these research conclusions based on different areas are quite various, and the entrepreneurial environment element system is also changing with time variation. Using these entrepreneurial environment element systems to directly analyze the entrepreneurial environment in deeply impoverished areas will result in ignoring the uniqueness and particularity of the entrepreneurial environment elements of deeply impoverished areas and reduc- 
ing the pertinence of policies and measures to optimize the entrepreneurial environment in deeply impoverished areas.

\section{Research Design}

The research has been divided into two phases. The first phase is exploratory research, in which interviews, Delphi method, and exploratory factor analysis have been applied to explore the entrepreneurial environment element system, and a questionnaire for entrepreneurial environment elements has been compiled based on these research works. In the second phase, a sample survey has been conducted, and a confirmatory factor analysis method has been used to verify the entrepreneurial environment element system.

\subsection{Exploratory Survey and Questionnaire Design}

In the exploratory investigation phase, 265 returned migrant entrepreneurs in the rural areas of northeast Chongqing were asked for key words on the entrepreneurial environment elements. Each of them returned 6 key words on the most urgent needs of the entrepreneurial environment. A total of 147 key words describing the entrepreneurial environment elements were obtained through single level encoding. On this basis, 20 entrepreneurial guidance experts were consulted with Delphi method. After three rounds of consultation, 23 relatively convergent entrepreneurial environment element entries were obtained, and a questionnaire was prepared based on this. A Likert five-point scale was used in the questionnaire, in which " 1 " means unimportant, and " 5 " means important.

\subsection{Sampling Survey and Data Acquisition}

As one of the Qinba mountainous areas, the concentrated contiguous poverty-stricken areas in northeast Chongqing (Yunyang, Fengjie, Chengkou, Wushan and Wuxi) are important ecological barriers of the three gorges reservoir area and important links of the Yangtze River economic belt strategy. In the formal survey phase, a two-stage sampling survey method was used to collect data. In the first stage, 10 deeply impoverished villages were taken from above 5 deeply impoverished counties in northeast Chongqing by simple random sampling; in the second stage, the list of migrant workers provided by the village committee was used as the sampling frame to perform simple random sampling. The online survey method was used to survey 842 returned migrant entrepreneurs, and 812 effective questionnaires were returned. The sample structure is shown in Table 1. The sample is randomly divided into two sub-samples according to the following sample structure ratio. The sample capacity of each sub-sample is 406 . Sub-sample 1 is used for exploratory factor analysis and sub-sample 2 is used for confirmatory factor analysis. Exploratory factor analysis method is used to refine the element (factor) structure of the entrepreneurial environment, and confirmatory factor analysis method is used to verify the reliability and validity of the entrepreneurial environment element structure. 
Table 1. The sample of the returned migrant workers to start businesses.

\begin{tabular}{cccc}
\hline Variable & Category & Number & Proportion (\%) \\
\hline \multirow{2}{*}{ Gender } & Male & 445 & 52.9 \\
& Female & 397 & 47.1 \\
\multirow{2}{*}{ Age } & Under the age of 25 (including 25) & 205 & 24.3 \\
& 26 years old - 35 years old & 330 & 39.2 \\
& Above the age of 36 (including 36) & 307 & 36.5 \\
\hline
\end{tabular}

\section{The Empirical Analysis of the Entrepreneurial Environment Element System}

\subsection{Extracting Entrepreneurial Environment Elements}

Exploratory factor analysis has been made into the data of subsample 1 to extract the entrepreneurial environment element system structure. The KMO test value is 0.846 , and the chi-square (or $\chi^{2}$ ) of Bartlett's Test of Sphericity is 1973.019, with a significant level of $P=0.000$, and the correlation matrix representing the data has a common factor, which is suitable for the factor analysis.

In exploratory factor analysis, firstly, variables have deleted one by one based on the criterion that the factor loading of the variable is less than 0.5 , and the Corrected Item-Total Correlation, (CITC) is less than 0.4. Five variables have been eliminated successively: "talent system" (factor loading is less than 0.5 , $C I T C=0.24$ ), "talent market" (factor loading is less than $0.5, C I T C=0.27$ ), and "entrepreneurial talent" (factor loading is less than $0.5, C I T C=0.31$ ), "tax reduction and exemption" (factor loading is less than 0.5, CITC $=0.35$ ), and "business incubation" (factor loading is less than $0.5, C I T C=0.37$ ); then, 4 variables with cross loading "venture capital", "financial credit", "infrastructure", and "labor costs" have been deleted one by one. Finally, 14 variables were retained, and 5 factors have been extracted according to Kaiser Criteria (Eigenvalue of the factor is greater than 1 ).

Table 2 is the Total Variance Explained table, and the software SPSS outputs the results of the common factors preliminarily refined through Principal Component Analysis method. The eigenvalue of factor 1 is 7.937, and the percent of Variance Explained is 33.071\%; the eigenvalue of factor 2 is 2.276 , and the percent of Variance Explained is $9.483 \%$. The former five factors explain $61.171 \%$ of the total variance, and exceed the $60 \%$ requirement, and the factor extraction results are ideal.

From the Rotated Component Matrix (Table 3) after Varimax with Kaiser Normalization, it can be seen that: tax policy, land circulation and government efficiency have a higher factor loading on factor $\mathrm{F}_{1}$; start-up capital, innovative talent, and technical support have a high factor loading on factor $\mathrm{F}_{2}$; family support, intermediary services, and public opinion and advocacy have a high factor loading on factor $\mathrm{F}_{3}$; financing costs, rent and land price, and consumption level have a higher factor loading on factor $\mathrm{F}_{4}$; registration convenience and registration fee have a higher factor loading on factor $\mathrm{F}_{5}$. 
Table 2. Total variance explained.

\begin{tabular}{cccccc}
\hline & \multicolumn{3}{c}{ Initial eigenvalue } & \multicolumn{2}{c}{ Rotated loading quadratic sum } \\
\cline { 2 - 6 } Factor & Total & Percent of variance & Accumulation \% & Percent of variance & Accumulation \% \\
\hline F1 & 7.937 & 33.071 & 33.071 & 17.668 & 17.668 \\
F2 & 2.276 & 9.483 & 42.554 & 13.133 & 30.802 \\
F3 & 1.600 & 6.666 & 49.220 & 12.917 & 43.718 \\
F4 & 1.518 & 6.324 & 55.545 & 10.524 & 54.243 \\
F5 & 1.350 & 5.626 & 61.171 & 7.540 & 61.783 \\
\hline
\end{tabular}

Table 3. The factor loading in exploratory factor analysis.

\begin{tabular}{cccccc}
\hline & $\mathrm{F}_{1}$ & $\mathrm{~F}_{2}$ & $\mathrm{~F}_{3}$ & $\mathrm{~F}_{4}$ & $\mathrm{~F}_{5}$ \\
\hline Tax policy & $\mathbf{0 . 8 0 2}$ & 0.296 & 0.117 & 0.078 & 0.071 \\
Land circulation & $\mathbf{0 . 7 8 2}$ & 0.160 & 0.082 & 0.224 & 0.079 \\
Government efficiency & $\mathbf{0 . 7 2 2}$ & 0.015 & 0.224 & 0.258 & 0.114 \\
Start-up capital & 0.410 & $\mathbf{0 . 6 7 4}$ & 0.252 & 0.087 & -0.045 \\
Innovative talent & 0.161 & $\mathbf{0 . 7 1 3}$ & 0.259 & 0.289 & 0.054 \\
Technical support & 0.135 & $\mathbf{0 . 6 3 0}$ & -0.109 & 0.244 & 0.229 \\
Family support & 0.301 & 0.133 & $\mathbf{0 . 7 4 7}$ & 0.209 & 0.067 \\
Intermediary services & -0.024 & 0.173 & $\mathbf{0 . 8 3 0}$ & 0.054 & 0.072 \\
Public opinion and advocacy & 0.260 & 0.197 & $\mathbf{0 . 7 4 2}$ & 0.116 & 0.186 \\
Financing costs & 0.059 & 0.239 & 0.130 & $\mathbf{0 . 7 7 5}$ & -0.130 \\
Rent and land price & 0.235 & 0.211 & 0.128 & $\mathbf{0 . 7 4 5}$ & 0.095 \\
Consumption level & 0.284 & 0.125 & 0.096 & $\mathbf{0 . 8 0 8}$ & 0.179 \\
Registration convenience & 0.131 & 0.136 & 0.003 & 0.046 & $\mathbf{0 . 8 8 5}$ \\
Registration fee & 0.057 & -0.050 & 0.263 & 0.039 & $\mathbf{0 . 8 1 4}$ \\
\hline
\end{tabular}

The five factors extracted after Varimax with Kaiser Normalization have relatively clear meanings. The factor $F_{1}$ reflects government policy and administrative efficiency, and is named "government and policy efficiency". The factor $\mathrm{F}_{2}$ reflects the production factors of capital, technology, and talent required in entrepreneurship and are named "production factor support"; Factor $\mathrm{F}_{3}$ reflects family support, social public opinion, and intermediary service support, and all three belong to social support for entrepreneurship and are named "family and social support"; Factor $\mathrm{F}_{4}$ reflects consumption level, rent and land price, and financing cost; these factors represent entrepreneurial cost and are named "entrepreneurial cost level"; factor $\mathrm{F}_{5}$ reflects the convenience of business registration which is named "business registration convenience". 


\subsection{Verifying the Entrepreneurial Environment Element System}

The data of subsample 2 are used to further make first order confirmatory factor analysis into the above five factors and their indexes to test the reliability and validity of extracting the entrepreneurial environment element structure. Model fitting results show that the model's absolute index $R M R=0.038, R M S E A=$ $0.047, G F I=0.956, \chi^{2} / d f=2.355$, parsimony index $P N F I=0.632, P G F I=0.578$; incremental index $R F I=0.943, I F I=0.972, N F I=0.939$. The degree of fitting of the model is well.

The statistical results are shown in Figure 1 and Table 4. The normalized factor loading of each index is greater than 0.7 , and $R^{2}$ is greater than 0.5 . The factor well interprets the index. The Cronbach's $\alpha$ value of the factor "government policy efficiency" index is 0.802 , the composite reliability $(C R)$ value is 0.833 , and the Average Variance extracted $(A V E)$ is 0.625 ; the Cronbach's $\alpha$ value of the factor "production factor support" index is 0.811 , the combined reliability $(C R)$ value is 0.867 , and the Average Variance extracted $(A V E)$ is 0.685 ; the Cronbach's $\alpha$ value of the factor "family and social support" index is 0.823 , the combined reliability $(C R)$ value is 0.870 , and the Average Variance extracted $(A V E)$ is 0.691 ; the Cronbach's $\alpha$ value of the factor "entrepreneurial cost level" index is 0.835 , the combined reliability $(C R)$ value is 0.814 , and the Average Variance extracted ( $A V E$ ) is 0.594 ; the Cronbach's $\alpha$ value of the factor "business registration convenience" index is 0.808 , the combined reliability $(C R)$ value is 0.648 , and the Average Variance extracted $(A V E)$ is 0.648 . The analyzed element structure of the entrepreneurial environment has better convergence validity. The $\sqrt{A V E}$ value of each factor is greater than the correlation coefficient between the factors. The entrepreneurial environment elements have better discriminate validity.

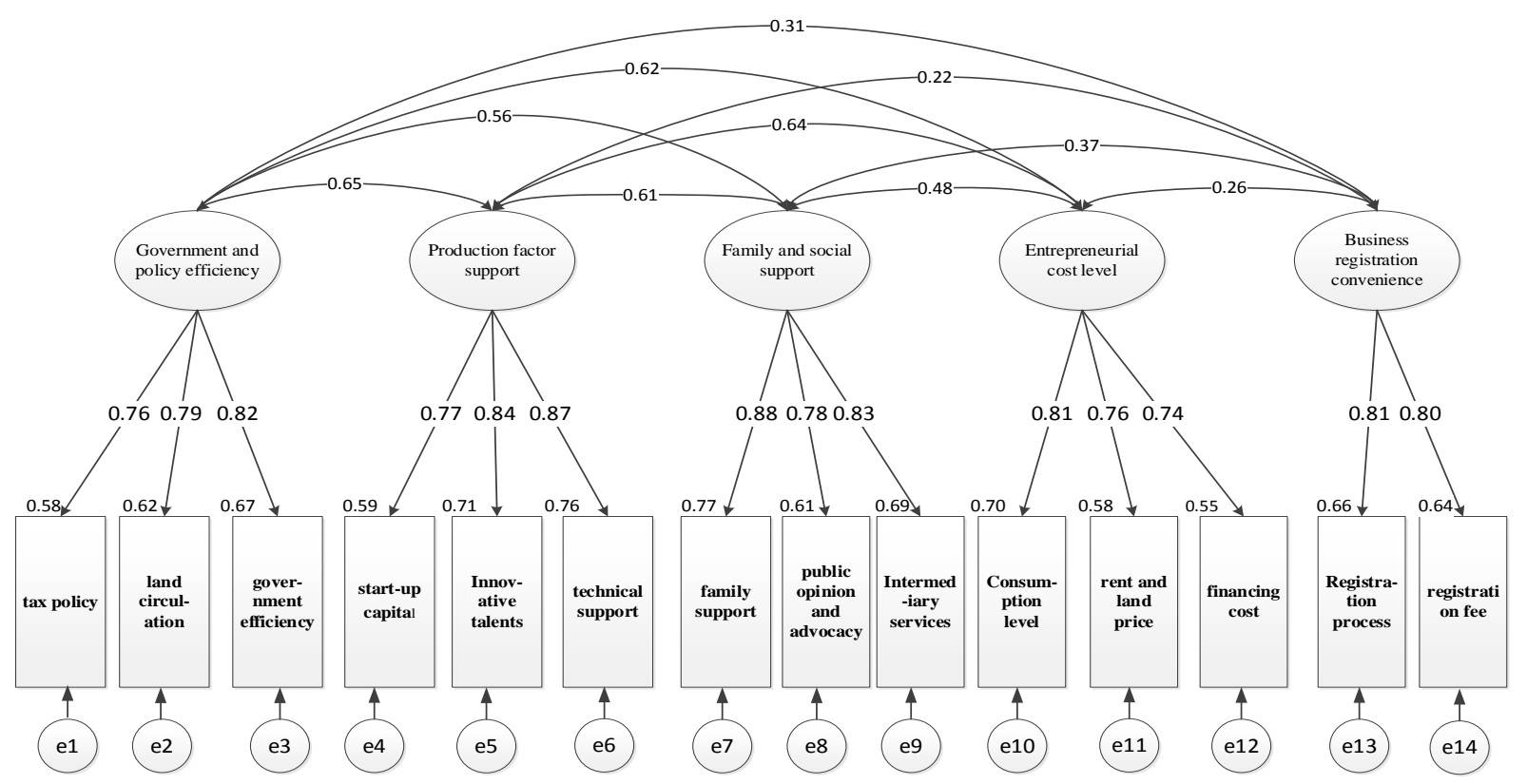

Figure 1. Verification results of the entrepreneurial environment element system. 
Table 4. Validity and reliability of entrepreneurial environment element verification.

\begin{tabular}{|c|c|c|c|c|c|c|c|c|}
\hline Latent variable & Item (index) & CITC & Normalized loading & $t$ & $R^{2}$ & Cronbach's $\alpha$ & $C R$ & $A V E$ \\
\hline \multirow{3}{*}{$\begin{array}{l}\text { Government and } \\
\text { policy efficiency }\end{array}$} & Tax policy & 0.644 & 0.76 & 11.23 & 0.58 & \multirow{3}{*}{0.802} & \multirow{3}{*}{0.833} & \multirow{3}{*}{$\begin{array}{l}0.625 \\
(0.791)\end{array}$} \\
\hline & Land circulation & 0.649 & 0.79 & 13.17 & 0.62 & & & \\
\hline & Government efficiency & 0.563 & 0.82 & 16.44 & 0.67 & & & \\
\hline \multirow{3}{*}{$\begin{array}{c}\text { Production } \\
\text { factor support }\end{array}$} & Start-up capital & 0.564 & 0.77 & 12.41 & 0.59 & \multirow{3}{*}{0.811} & \multirow{3}{*}{0.867} & \multirow{3}{*}{$\begin{array}{c}0.685 \\
(0.828)\end{array}$} \\
\hline & Innovative talent & 0.604 & 0.84 & 10.52 & 0.71 & & & \\
\hline & Technical support & 0.410 & 0.87 & 9.13 & 0.76 & & & \\
\hline \multirow[b]{2}{*}{$\begin{array}{l}\text { Family and social } \\
\text { support }\end{array}$} & Family support & 0.665 & 0.88 & 32.20 & 0.77 & \multirow[b]{2}{*}{0.823} & \multirow[b]{2}{*}{0.870} & \multirow[b]{2}{*}{$\begin{array}{c}0.691 \\
(0.831)\end{array}$} \\
\hline & Public opinion and advocacy & 0.657 & 0.78 & 14.12 & 0.61 & & & \\
\hline \multirow{3}{*}{$\begin{array}{c}\text { Entrepreneurial } \\
\text { cost level }\end{array}$} & Consumption level & 0.683 & 0.81 & 14.14 & 0.70 & \multirow{3}{*}{0.835} & \multirow{3}{*}{0.814} & \multirow{3}{*}{$\begin{array}{c}0.594 \\
(0.771)\end{array}$} \\
\hline & Rent and land price & 0.605 & 0.76 & 11.91 & 0.58 & & & \\
\hline & Financing cost & 0.571 & 0.74 & 11.41 & 0.55 & & & \\
\hline \multirow{2}{*}{$\begin{array}{l}\text { Business } \\
\text { registration } \\
\text { convenience }\end{array}$} & Registration process & 0.552 & 0.81 & 14.25 & 0.66 & \multirow{2}{*}{0.808} & \multirow{2}{*}{0.648} & \multirow{2}{*}{$\begin{array}{c}0.648 \\
(0.805)\end{array}$} \\
\hline & Registration fee & 0.552 & 0.80 & 16.73 & 0.64 & & & \\
\hline
\end{tabular}

It can be seen that the basic content of the five-dimensional entrepreneurial environment element system of the deeply impoverished area in northeast Chongqing is consistent with the research conclusions of domestic and foreign scholars (Dill, 1958; Thébaud, 2015; Nagler \& Naudé, 2017; Gartner \& Shane, 1995; Xiao et al., 2018; Zhang, 2018) on living standards, financing costs, intermediary services, talent technology, and family support. But the basic content also has its own unique characteristics: public opinion and advocacy, business registration, land circulation, and rent and land price have become important elements of the entrepreneurial environment, which is very distinctive from the entrepreneurial environment elements of other areas at home and abroad. It reflects the important characteristics of the entrepreneurial environment elements of the deeply impoverished areas in northeast Chongqing in terms of entrepreneurial ideas, administrative efficiency, and talent gathering, which provides a basis for optimizing the entrepreneurial environment of the deeply impoverished areas in northeast Chongqing.

\section{Measures to Optimize the Entrepreneurial Environment of the Deeply Impoverished Area in Northeast Chongqing}

The deeply impoverished areas vary in the economic development level, social culture and other aspects, and also have both similarities and uniqueness in the entrepreneurial environment elements. Based on the above entrepreneurial environment element system of the deeply impoverished areas, the following measures are raised to optimize the entrepreneurial environment in the deeply impoverished areas. 
1) Improve the efficiency of government administration and increase the support from entrepreneurial policies

In the entrepreneurial environment element of the deeply impoverished areas, government policies and administrative efficiency are different from other research conclusions in contents, mainly reflecting in land circulation and tax policies. Therefore, in the first place, land circulation policy should be innovated to help entrepreneurs overcome the difficulties of land circulation. The first method is to stimulate multiple entities to participate in land circulation through policies to achieve moderate scale operations; the second method is to innovate land circulation methods, actively push mature circulation methods, and encourage the exploration of new circulation methods; the third is to establish and protect the usufruct of stakeholders to ensure orderly and long-term circulation of land; in the second place, tax support for entrepreneurship should be strengthened. The first method is to effectively implement the existing preferential tax policies for entrepreneurship. The second is to introduce a targeted business tax support policy according to the actual situation in the deeply impoverished areas. The third is to improve the efficiency of government administration. Probably, the returned rural entrepreneurs in deeply impoverished areas are neither familiar with the functional management departments related to entrepreneurship, nor the processes of government affairs. Therefore, relevant functional departments need to adopt multiple methods such as on-site and telephone consulting and answering to improve administrative efficiency.

2) Construct diversified channels and strengthen the support for entrepreneurial production factors

Funding, talent, and technology are the three major problems confronted by entrepreneurs, which are especially rigorous for migrant workers in deep impoverished areas. With an aim to construct diversified channels and strengthen the support for entrepreneurial production factors, it is necessary to take the market mechanism as the lead and the government as the guide to gradually form a support system including financial institutions, universities, research institutes, and consulting agencies for entrepreneurial production factors. First of all, in terms of the fund support for entrepreneurship, one method is to strengthen financial fund support for entrepreneurship, give full play to the efficiency of poverty alleviation funds, organically integrate entrepreneurship and poverty alleviation, and realize the transformation from blood transfusion to poverty alleviation through entrepreneurship support; the second is to advance financial institutions, guarantee institutions, venture capital institutions, etc. to form a financial system to serve entrepreneurship, and provide entrepreneurs with efficient and convenient financial services. Secondly, in terms of talents and technology, efforts should be channeled into vigorously promoting industry-university-research cooperation and propelling universities, research institutions, and consulting service institutions to form pairing entrepreneurship assistance systems in deeply impoverished areas. The first method is to establish a mechanism with professional and technical personnel going to the countryside 
to provide on-site assistance and targeted technical training for entrepreneurs; the second method is to make use of internships and practical training university students to accelerate the entrepreneurial activities and alleviate the bottleneck of talents in entrepreneurship.

3) Create an entrepreneurial atmosphere and improve social support for entrepreneurial families

Distinctive from other research conclusions on the rural entrepreneurial environment elements, the returned rural migrant workers in the deeply impoverished areas badly need the support of family, social public opinion and social intermediaries in entrepreneurship. In view of this, first of all, in terms of family support, the first method is to shape the spirit of advocating entrepreneurship through dissemination of social media and other channels, and positively affect the attitudes of family members toward entrepreneurship so as to help entrepreneurs seek spiritual inspiration and action support from the family; the second method is to strengthen the entrepreneurial organization work of rural grass-roots government organizations, advance grass-roots government organizations to communicate with entrepreneurs and their family members in various ways, such as forums, in order to enhance family support for entrepreneurs. In the second place, in terms of social public opinion and intermediary support, firstly, the government should take the lead and build a diversified media platform to systematically promote the typical model of entrepreneurship and enhance the self-efficacy of returned migrant workers in entrepreneurship. The second is to spread the entrepreneurial culture and entrepreneurial spirit, vigorously guide the value orientation of entrepreneurship, and effectively establish the concept of advocating entrepreneurship and serving entrepreneurship. The third is to build an entrepreneurial support system with government as the lead, social institutions and groups as co-participants to comprehensively support the returned migrant workers to start businesses in their hometowns.

4) Directly supply entrepreneurial resources and reduce the overall cost of entrepreneurship

The entrepreneurial cost level is an important entrepreneurial environment element of deeply impoverished areas. Returned migrant workers face tremendous pressure from high entrepreneurial costs in entrepreneurship, including the cost of production materials, labor costs, and logistics and transportation costs. For this reason, it is necessary to establish direct supply channels and direct subsidy channels. The first is to establish a link between producers of production materials and returned rural entrepreneurs, and establish direct regional supply channels for producers of production materials to reduce the overall cost of producing materials. The second is to integrate and perfect the rural logistics system, give play to the intensive advantages of rural logistics and reduce logistics transportation costs. The third is to improve the availability factor of agricultural subsidy funds, get rid of the current equalitarianism in disposing various agricultural subsidy funds and poverty alleviation funds, and establish a direct subsidy mechanism to improve the availability factor of subsidy funds. 
In addition, as to business registration, the traditional thinking pattern should be broken and the ways of business registration should be innovated to provide convenient registration services for returned migrant workers to start businesses. A joint registration service group can be formed by the Administration of Industry and Commerce, the Taxation Bureau, and the banks to make full use of network information technology to provide timely online registration guidance and on-site "one-stop" registration services, which will accordingly simplify procedures and improve efficiency.

\section{Researches and Prospects}

This paper studies the elements of the entrepreneurial environment of migrant workers returning home and puts forward some measures to optimize the entrepreneurial environment. At the same time, the follow-up research also was thought about. First of all, this paper only studies the composition of entrepreneurial environment, however, the entrepreneurial environment must be recognized by migrant workers to form entrepreneurial intention and motivation. Follow-up research is necessary to further explore the formation mechanism of migrant workers' cognition of entrepreneurial environment. Secondly, on the basis of analyzing the formation mechanism of entrepreneurial environment cognition, it is necessary to further analyze the mechanism of entrepreneurial environment cognition on entrepreneurial behavior.

\section{Conflicts of Interest}

The authors declare no conflicts of interest regarding the publication of this paper.

\section{References}

Chen, N., \& Du, L. (2018). The Evaluation of Entrepreneurial Environment of Farmers Based on Family Farm. Journal of Northwest Agricultural and Forestry University of Science and Technology, 1, 50-57.

Chi, R. Y. (2002). A Comparative Study on the Entrepreneurial Environment between the United States and Japan. Foreign Economy and Management, 9, 7-13.

Dill, W. R. (1958). Environment as an Influence on Managerial Autonomy. Administrative Science Quarterly, 3, 409-443. https://doi.org/10.2307/2390794

Gartner, W. B., \& Shane, S. A. (1995). Measuring Entrepreneurship over Time. Journal of Business Venturing, 10, 283-301. https://doi.org/10.1016/0883-9026(94)00037-U

Gnyawali, D. R., \& Fogel, D. S. (1994). Environments for Entrepreneurship Development: Key Dimensions and Research Implications. Entrepreneurship. Theory \& Practice, 4, 43-62. https://doi.org/10.1177/104225879401800403

Hang, Y. (2016). Analysis on Management of Entrepreneurial Environment for Migrant Workers. Asian Agricultural Research, 1, 79-82.

Katonáné, J. (2015). Building an Entrepreneurial Environment in Rural Regions: A Possible Way to Develop Human and Social Capital. Studies in Agricultural Economics, 117, 20-26. https://doi.org/10.7896/j.1428

Marian, H. (2015). Entrepreneurial Environment in Slovakia: Multi-Perspective Compar- 
ison with Innovation-Driven Economies. Procedia Economics and Finance, 4, 437-444. https://doi.org/10.1016/S2212-5671(15)01652-4

Nagler, P., \& Naudé, W. (2017). Non-Farm Entrepreneurship in Rural Sub-Saharan Africa: New Empirical Evidence. Food Policy, 67, 175-191. https://doi.org/10.1016/j.foodpol.2016.09.019

Patti, D. M. A., \& Mudambi, R. (2016). A Tale of Soil and Seeds: The External Environment and Entrepreneurial Entry. Small Business Economics, 4, 955-980. https://doi.org/10.1007/s11187-016-9744-7

Selin, D. (2018). Varieties of Entrepreneurship: Exploring the Institutional Foundations of Different Entrepreneurship Types through 'Varieties-of-Capitalism' Arguments. Small Business Economics, 2, 293-320. https://doi.org/10.1007/s11187-018-0002-Z

Thébaud, S. (2015). Business as Plan B: Institutional Foundations of Gender Inequality in Entrepreneurship across 24 Industrialized Countries. Administrative Science Quarterly, 4, 671-711. https://doi.org/10.1177/0001839215591627

Xiao, Z. Z., Huang, Y., Cheng, Z. Y., \& Ling, L. (2018). Research on the Mechanism of the Impact of Innovation and Entrepreneurship Environment on the Choice of Household Assets of Farmers Entering the City. Economic Review, 5, 148-159.

Zhang, D. (2018). Study on the Evaluation of Entrepreneurial Environment in Underdeveloped Areas of China. Commercial Economy, 1, 119-120.

Zoltan, J. A., \& Saul, E. (2018). Entrepreneurship, Institutional Economics, and Economic Growth: An Ecosystem Perspective. Small Business Economics, 2, 501-514.

https://doi.org/10.1007/s11187-018-0013-9 